\title{
PAISAGEM E PROTEÇÃO AMBIENTAL: ALGUMAS REFLEXÕES SOBRE CONCEITOS, DESENHO E GESTÃO DO ESPAÇO
}

\section{HELENA NAPOLEON DEGREAS}

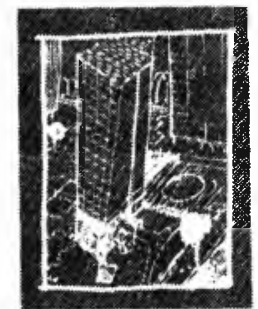

Água, solo, fauna e flora, compõem os bens naturais mais preciosos que possui a terra: local onde reside e do qual também faz parte o homem. Por esta razão, seu planejamento, proteção, desenho e intervenção devem objetivar a composição ideal do ambiente humano. A natureza (descrita como aa situação que não fọi alterada pelo esforço humano) se converte em paisagem quando nos referimos aos seus componentes naturais, suas peculiaridades fisiográficas e ambientais; também se transforma, alterando suas características próprias de acordo com as influências históricas, culturais e tecnológicas do homem, refletindo, por conseqüência, pelos sistemas climáticos, naturais e sociais, a materialização de um momento da sociedade.

Composta por uma infinidade de objetos naturais e artificiais, a paisagem representa uma situação fixa; o acúmulo de objetos mortos sem significado para a sociedade. Como à vida em sociedade pressupõe uma multiplicidade de funções, usos e atitudes, a paisagem altera seu significado: do relacionamento social com os objetos naturais e artificiais tem-se o espaço, organizando-se aí os lugares de vida da população (Santos, 1986). Inevitavelmente, o enfoque que é dado ao uso e desenho atual do espaço que ainda conserva características naturais, estará sempre condicionado à percepção que se tem da paisagem e à postura ante o ambiente natural, sendo influenciados pelo local, pela cultura da sociedade e posicionados dentro de um momento histórico.

As palavras planejamento, uso, desenho e função, surgem para o homem (ser social) numa organização de objetos capazes de satisfazer suas necessidades biológicas e sociais, pela criação de espaços (Santos, 1986); da adequação do suporte físico ambiental às necessidades humanas tem-se a arquitetura da paisagem.

Se paisagem é espaço, quando ocorre o relacionamento social com os elementos que a compõem, também é ecossistema quando acrescida à vida, 
transformando-se então numa situação que se apresenta em constante processo de recriação, evolução e transformação (Lyle, 1987; Odum, s.d.).

Ao avaliar-se a qualidade ambiental está-se discutindo diretamente a qualidade das intervenções humanas sobre um suporte físico, relacionando-se os impactos criados aos graus de inadequação das atitudes e concretizações humanas sobre um ecossistema.

Neste ponto, o profissional que trabalha com a paisagem alterando-a pelo desenho ou pelo projeto, deve compreender que por mais abstrata que possa parecer sua idéia, esta última pressupõe a concretização de uma atitude premeditada e consciente; projeta-se pensando na recriação de paisagens, "materialização de um momento da sociedade" (Santos, 1986), acrescentandose objetos ou intenções numa situação erroneamente considerada estática e não na recriação de um ecossistema. Paisagens são como fotos de uma realidade (Santos, 1986) e, ambientes passam por uma evolução constante, não estando jamais parados ou representando uma situação estática no tempo (Odum, s.d.).

Acrescentar elementos à paisagem significa que esses objetos devem fazer parte, compor e também auxiliar no processo de recriação de ecossistemas (lugares com vida). Além de objetos fixos, materiais, a paisagem, enquanto espaço repleto de funções, também é de intenções políticas, econômicas e sociais que formam, apesar de características abstratas, um desenho específico no espaço. Sua dimensão se altera; ultrapassa a condição de lugar geográfico ou mero ecossistema, representando uma localização de caráter humano que extrapola os limites ambientais, ecológicos, administrativos ou nacionais; é um espaço universal.

Organiza-se o espaço social, funcional, etc., o mesmo não ocorrendo quanto ao ecossistema sobre o qual essas abstrações se concretizam.

A crença de que o fenômeno urbano é uma entidade separada da "natureza" e de que os seus processos de evolução são sempre catastróficos tem dominado a maneira pela qual o ecossistema urbano é percebido e construído, separando-o cada vez mais de suas raízes naturais (Drew). Neste ponto os discursos ecológicos entram de maneira crucial quanto à discussão sobre preservação, mas não com o devido enfoque, uma vez que em sua maioria apresentam uma visão compartimentada da realidade demonstrada através de seu discurso e atitudes parciais, que defendem a preservação desta ou daquela espécie, como elementos individuais do espaço, sem qualquer tipo de relação com 
as demais formas vivas; verdadeiros tótens onde o ser humano não deve chegar ou tocar.

O homem através de seu conhecimento técnico já alcançou todos os espaços terrestres transformando ecossistemas de características naturais em paisagens artificiais, dando-lhes funções. Na sua necessidade quase atávica (Ab'Saber) de dominação da paisagem natural, ou até de domesticação, destruiu e alterou praticamente tudo que mantivesse qualquer tipo de semelhança agreste ou selvagem, uma vez que não foi capaz de compreender a lógica de composição e ordenação do ambiente que ele alterou; e, ainda pior, não foi capaz de recriar uma situação estável que obedecesse às mesmas ordenações.

Fazendo uma analogia da paisagem ao nosso planeta, temos que a Terra funciona como uma máquina, um sistema gigantesco. Como máquina ela é composta por inúmeras partes, milhares de engrenagens, ou subsistemas que trabalham como uma unidade ligados por fluxos de energia e matéria que a mantém viva (Odum, 1986).

A paisagem, mais do que expressão visível de objetos, é componente de uma realidade maior que nem sempre é apreendida com um olhar (Burle Marx, 1986). Das trocas de fluxos e energias dependem inúmeros outros componentes para a sua sobrevivência. A intervenção do homem nos processos naturais se dá não só nas alterações de formas e objetos (naturais ou artificiais) de paisagens estáticas ou consideradas como realidades completas, sem nenhuma relação com o restante de seu entorno, como também, nosso projeto, lei ou plano, influi diretamente nos fluxos de energia e de matéria, alterando suas correntes, sua magnitude, ou diminuindo depósitos materiais de energia.

O maior desafio para quem trabalha com paisagens e ambientes é compreender o seu projeto enquanto realidade completa, que tem vida própria, mas que de sua ligação com a paisagem e o ecossistema que sofreu a intervenção, depende a sua sobrevivência, sucesso ou fracasso. É preciso intervir numa realidade dialética, compreendendo seus componentes, estruturas e funcionamento; deve-se fugir do pensamento e das atitudes que nos levam à "dominação" da natureza, alcançando-se a participação racional em seu processo de criação. Um desenho, obtido por uma delimitação de proteção é premeditado e previsível, configurando portanto escolhas intencionais e conscientes. Nossa criação de ecossistemas tem sempre sido casuística, sem a compreensão lógica de como os processos naturais ocorrem, e, além do mais, sem qualquer previsão de como os novos ecossistemas irão trabalhar ou, 
ainda, sem a compreensão de que eles realmente fazem parte e são um ecòssistema. Os sistemas naturais são auto-organizáveis e podermos alterá-los e recriá-los através da compreensão dos princípios com os quais eles trabalham, para transformar os ecossistemas humanos em ecossistemas sustentados e, portanto, equilibrados (Lyle, 1985).

\section{EVOLUÇÃO DAS POLÍTICAS AMBIENTAIS}

A humanidade faz parte da natureza e depende dela para a sua sobrevivência, mas é a civilização (através de sua postura cultural) que dá a ela o poder de alterá-la em escala sempre crescente, de maneira adequada ou não. Para Viola (Toynbee, 1982) o comportamento predatório humano não é novo na história, tendo através de profundas crises ecológicas feito desaparecer civilizações inteiras. Estando na $3^{\text {a }}$ fase de nossa história (Drew, 1983), denominada de Fase da Agressão e da Conquista, graças à liberação dos condicionantes físicos e limitações da natureza, o que de fato aparece é a escala dos instrumentos de predação. Conseguimos finalmente, mas não felizmente, chegar à capacidade de auto-extermínio consciente (armas nucleares) através de atuações calcadas na previsão da Terra como fonte infinita de recursos renováveis (Drew, 1983, p. 4).

Neste ponto, a mudança do comportamento humano é possível, uma vez que alterações nos sistemas espaciais são deliberadas e modeladas para fins determinados. A pesquisa entra não só como provedora de dados, informações, mas seus efeitos influenciam na percepção dos fatos, e por conseqüência na maneira pela qual a sociedade e, principalmente os governantes vêem o mundo. "Ela influência o que eles encaram como fato ou ficção, os problemas que vêem ou não, as interpretações do que eles encaram como plausíveis ou sem sentido; os julgamentos que fazem de uma política ser potencialmente efetiva ou irrelevante." (Berry, 1977, p. 2).

Dentro da visão ecossistêmica para a percepção assumida por Berry (1977), no circuito retroalimentador, os processos são geradores de comportamento espacial, baseados em contextos ambientais e guiados pela combinação de necessidades biológicas (sobrevivência, manutenção, reprodução) e impulsos culturais (necessidades de sucesso construídas dentro do sistema nervoso central dos indivíduos em sociedades que apresentam progressos econômicos e tecnológicos através de atitudes e pressões culturais).

Temos ainda, com o mesmo autor, que, o que o homem faz, é determinado pelo que o homem acredita; a percepção é, então, por sua vez, um produto das necessidades biológicas, dotes naturais, visão mundial do agente, basea- 
das nos valores de sua cultura e os papéis, esperanças e aspirações impostos aos seus membros, juntamente com os frutos do aprendizado baseados na experiência com os resultados de tomadas de decisões e ações anteriores. Acrescenta que as decisões são apenas traduzidas em ação quando conflitos com outros agentes tenham sido resolvidos, sendo assim resolvido o novo conflito e provida a reavaliação do circuito retroalimentador.

Quanto aos governados, estes, através de alguns poucos representantes, começaram a ser ouvidos desde a década de 70 , por meio de movimentos ecológicos. Epoca representada pelo despertar da consciência ecológica no mundo (Conferência das Nações Unidas sobre o Meio Ambiente em Estocolmo - 1972, entre outros).

Viola (1987, p. 6) comenta que é nessa época que os problemas de degradação do ambiente associadas ao crescimento econômico foram percebidos através de uma perspectiva global que superava as diversas questões pontuais, discutidas por agências estatais na década de 50 e 60, dos países do Primeiro Mundo. Ainda de acordo com ele, os movimentos ecológicos são portadores de valores e interesses universais que ultrapassam as fronteiras de classe, sexo, raça e idade, tendo a possibilidade de incorporar a grande maioria da humanidade.

Todos os fatos levam à preocupação com o papel das ideologias e valores na determinação da natureza dos processos espaciais. Parece então evidente que, para entrar-se numa nova fase que se projeta no futuro, era de responsabilidade e unidade, onde a compreensão e percepção do funcionamento da natureza é fruto de uma consciência social e uma adaptação sensível das condições ambientais (Gutkind, s.d.) a pesquisa proposta por Berry (1977) entra de maneira crucial, na medida em que o futurólogo, ao tentar evitar um acontecimento, prevê imagens do futuro indicando uma cadeia de alternativas que estimula uma marcada mudança no comportamento social, fazendo com que tenhamos capacidade de discenir o que devemos conseguir ou evitar. Acrescenta ainda que a mudança social mais importante de nosso tempo é a difusão da tomada de consciência de que temos capacidade de lutar e deliberadamente planificar a própria mudança.

Viola (1987, p. 19) coloca que atualmente estamos entrando numa nova fase, denominda Ecopolítica e que no Brasil, os movimentos ecológicos adquirem certa relevância. Acrescenta que nos três períodos no movimento ecológico no Brasil, a primeira fase, chamada de ambientalista desde 1974 até 1981, foi caracterizada pela denúncia de degradação ambiental nas cidades e nas comunidades alternativas rurais; uma segunda fase, que chamou de transição, 
desde 1982 até 1985, foi caracterizada pela confluência parcial e politização explícita progressiva dos movimentos, além de uma grande expansão qualitativa e quantitativa dos mesmos. A terceira fase, que estamos adentrando chamou de ecopolítica, vem ocorrendo desde 1986. Essa ecologia política faz do valor de sobrevivência, respeito dos sistemas vivos e resistência à destruição da vida, o fundamento necessário para a construção e legitimação de um sistema de valores sóciopolíticos. É nesse momento que a maioria do movimento ecológico auto-identifica-se como político e decide participar ativamente na arena parlamentar (Viola, 1987), estando desta maneira deliberadamente planificando nossa mudança e partindo, para políticas mais responsáveis.

A discussão e implementação dessas políticas é um fato novo, tendo vigorado até pouco tempo, a completa desproteção do ambiente, não existindo nenhuma norma que proibisse a devastação das florestas, assoreamento de rios, erosão de terras ou a qualquer tipo de ameaça que se fizesse ao delicado equilíbrio ecológico. A atuação do poder público na proteção do meio ambiente sempre esbarrava na concepção individualista da propriedade e, trabalhar com isso, incorreria numa limitação daquele direito.

Apenas com a multiplicação dos problemas causados pela poluição, ou pelo efeito de uma atividade que causasse deterioração ambiental, aliado à escassez de recursos, é que houve interesse em criar dispositivos e ações de controle, procurando minimizá-los. Grande parte dessas ações resultaram a partir de pressões exercidas por entidades profissionais ou pela necessidade de se manter o sistema produtivo, que por muitas vezes era ameaçado pela poluição por ele causada.

Nas áreas consideradas "rurais", a ameaça a qualquer tipo de equilibrio ecológico não era sentida, graças à visão de fartura e abundância de terras e recursos; a conquista de novos territórios e a predominância de uma agricultura de caráter predatório era permitida pela sociedade quando não incentivada.

Assim foi nas cidades, onde se concentravam as atividades econômicas, concentravam-se também os problemas ambientais delas decorrentes e onde iniciaram-se as gestões para minimizar os conflitos que começaram a se intensificar. No final do séc. XIX já tinha sido criado o Serviço Sanitário do Estado de São Paulo e promulgado o Código Sanitário, onde era estabelecida uma classificação das indústrias em incômodas, perigosas, insalubres, estipulandose ainda regras com vistas à proteção da saúde pública. 
$\mathrm{Na}$ década de 20 algumas ações governamentais procuraram ampliar a atuação pública sobre as questões ambientais, incluindo medidas relativas à proteção da fauna aquática do estado de São Paulo. A nível federal, a década de 30 é o marco inicial da atuação mais decisiva na proteção ambiental com a promulgação de decretos que estabeleciam medidas de proteção aos animais; e organizavam a proteção do patrimônio histórico e artístico nacional, através da criação de alguns parques nacionais.

Acrescentamos que durante a década, a nível internacional, os planos criados tratavam de assuntos referentes à conservação do solo, gestão de recursos hídricos e programas de bacias. Nos anos 40 o enfoque principal das discussões estava direcionado para o aumento das indústrias químicas e conseqüente poluição ocasionada pelos produtos tóxicos delas provenientes, embalados pelas teorias malthusianas, onde pregava-se a finitude dos recursos terrenos. Diante dessas posições, a nível nacional, nenhuma atitude significativa foi tomada.

Durante a década de 50 surgem alguns problemas críticos de contaminação das águas e do ar (graças ao seu desenvolvimento econômico e industrial) em vários locais do estado de São Paulo, tendo sido desencadeados vários mecanismos de controle, entre outros, a proibição do lançamento de resíduos que prejudicassem a qualidade dos cursos d'água. A nível federal, as ações se concentraram basicamente na criação de áreas florestais protegidas.

Nos anos 60, internacionalmente, os assuntos mais discutidos eram aqueles que davam maior ênfase na melhoria e manutenção da qualidade ambiental. Para tanto, criaram-se padrões e regulamentos que controlassem a qualidade do ar e das águas; que preservassem paisagens naturais e recursos cênicos (lembrando sempre que a discussão de potenciais não ficava apenas no padrão cênico, e sim, enquanto valor de paisagem que deveria ser preservado para o mundo e para a estabilidade ecológica, como meio de se alcançar a qualidade do meio ambiente - final do século passado/EUA); e preservação das espécies ameaçadas de extinção.

É interessante observar que os princípios internacionais exercem sobre as ordenações estatais certo grau de influência, obrigando-as a rever posturas acanhadas que são peculiaridades a cada legislação estatal (Costa, 1981, p. 11). A respeito disso, podemos exemplificar com a década de 70 , quando os efeitos nocivos do crescimento urbano desordenados se fizeram sentir mais fortemente e mais especificamente à Declaração da Conferência das Nações Unidas sobre o Ambiente Humano, levado a efeito em Estocolmo, 1972. 
Com este marco histórico, fica esclarecido que atribuir os problemas do ambiente unicamente às interações entre os componentes biológicos e físicos é, no mínimo, superficial. Magnoli (1984) ainda acrescenta que foi possível identificar na época dois níveis distintos de abordagem para as soluções propostas; o primeiro deles, denominado de Nível das Partes (merístico) que compreendia ações isoladas para problemas específicos e pontuais, e que serviria apenas como paliativo; numa segunda abordagem, o Nível da Globalidade (ponto de vista holístico), onde se procuram soluções globais à problemática também global do meio ambiente. Neste último aspecto tornou-se claro que o conhecimento do meio ambiente requer analisar as vinculações entre as estruturas sociais e as estruturas naturais.

Por volta desse mesmo período é que se iniciam os esforços para uma política ambiental mais abrangente no Brasil. Segundo Kazuo (1985) procedeu-se em 1972 um levantamento entre os nove ministérios e uma secretaria de Estado, de pelo menos 34 organismos públicos que mantinham implicações diretas ou indiretas com assuntos ambientais. Diante de tal dispersão alguns passos foram dados, culminando com medidas institucionais básicas. A primeira foi a criação, em 1973, da SUPREM, Superintendência dos Recursos Naturais, cujo objetivo entre outros era de tratar de recursos naturais como um todo, o que era impossível de se atingir diante da multiplicidade de órgãos existentes.

Nos anos 80, no âmbito internacional, tem-se o questionamento sobre a eficiência das normas e procedimentos da última década e a exigência, pelas instituições financeiras, sob a pressão dos ambientalistas, dos relatórios de impacto ambiental de projetos por ela financiados.

Pelo exposto, temos que as questões ambientais começaram e ainda hoje são tratadas de forma setorial (ar, solo, fauna...), servindo assim, as soluções, como paliativos que sequer chegam a uma definição ou estratégia global sobre essa problemática. Isto levou à criação de vários órgãos e leis que na maioria dos casos tinham funções superpostas quando não conflitantes. Embora exista um esforço de se implantar uma política ambiental coordenando as ações de vários órgãos ligados à questão, somados ao que efetivamente foi realizado no sentido institucional, observa-se que muitos dos objetivos não foram plenamente atingidos ficando a maior parte apenas nas delimitações e no papel, sendo alvo de toda sorte de agressão e degradação.

Acrescentamos que isso tem ocorrido principalmente pela forma com que a questão ambiental tem sido tratada, colocando que a contraposição entre a questão ambiental e o desenvolvimento econômico tem levado os governantes (acrescentamos a sociedade também) a optarem pela segunda questão, fi- 
cando o ambiente em plano secundário e considerado como problema. Isto acaba se revelando, nas carências de recursos financeiros e humanos entre outras, para que o aparelho do Estado possa realmente conduzir e efetivar uma política ambiental.

A evolução das políticas ambientais através dos tempos aliada à necessidade de uma conceituação teórica serviu muito bem para posicionar a questão ambiental no contexto atual de nossa sociedade, verificando-se que essa situação é completamente correta dentro do ponto histórico em que estamos. Sintetizando as idéias de Berry (1975) temos que o que hoje fazemos é determinado por aquilo que acreditamos. Assim, Estado e Sociedade criam suas paisagens e seus espaços da maneira que consideram correta e de acordo com o pensamento reinante. Para explicar os conflitos ecológicos e ambientais promovidos por alguns grupos de maneira marcante desde 1970, e que de uma certa forma "quebram" a tranqüilidade do pensamento reinante, pode-se acrescentar algumas idéias de Santos (1985, p. 21):

"A introdução da dimensão temporal no estudo da organização do espaço envolve considerações numa escala muito ampla, isto é, uma escala mundial. $O$ comportamento dos subespaços do mundo desenvolvido está geralmente determinado pelas necessidades das nações que estão no centro do sistema mundial..." Revendo algumas posições, temos que no âmbito internacional questionou-se na década de 80 a eficiência de normas, procedimentos e técnicas adotadas para alteração de paisagens e ambientes, enquanto a nível nacional essas questões são tratadas setorialmente e sem definição global; e, ainda pior, como diz Lyle (1985) sem inclusive percebermos que estamos atuando sobre um outro sistema, alterando-o de forma irreversível e, apesar de incorreta, premeditadamente.

"... A dimensão histórica ou temporal é assim necessária para se ir além do nível de análise ecológica. A situação atual depende, por isso, de influências impostas... A noção de espaço é assim inseparável da idéia de sistemas de tempo. A cada momento da história local, regional, nacional ou mundial, a ação das diversas variáveis depende das condições do correspondente sistema temporal..." (Santos, 1985, p. 21). Acrescenta, ainda, que o significado de uma mesma variável muda no decurso do tempo, isto é, na história do lugar; dessa forma, a mera referência a uma situação histórica ou a busca de explicações parciais concernentes a um ou outro dos elementos do conjunto não são suficientes, pois representariam situações atuais como se elas fossem um resultado de suas próprias condições no passado. $O$ que interessa então é a sucessão de sistemas e não de elementos isolados. 
Fatalmente, pelo que foi exposto, estaremos caminhando irremediavelmente para a ecopolítica a que se refere Viola (1986), embora ela ainda não estivesse presente no discurso da Nova República e ainda não possamos avaliar o que hoje, em 1990, esteja a atual administração federal pretendendo. Ainda de acordo com o mesmo autor, o que se pregava na administração passada, estava totalmente concentrado no crescimento econômico e na necessidade de uma melhor distribuição de renda, sendo esse segundo aspecto secundário no discurso do regime anterior; quanto à questão ambiental, ela sequer estava presente. Hoje, o discurso parece o mesmo só que acrescido dessa última questão. Como, com que meios, instrumentos, programas, para que e para quem, não somos capazes de dizer; apenas sabemos que (enfim!) a sociedade começa a perceber que o nível de degradação ambiental aumenta e que algo tem de ser feito para deter esse processo, quebrando aos poucos a visão bucólica de paisagem e ambiente, como retratos de uma realidade idealizada, perfeita e infinita em riquezas e recursos, sedimentada sobre governantes e governados. Percebe-se desde a $1^{\text {a }}$ Conferência de Estocolmo, em 1972, que à abordagem ecológica e auto-sustentada também deveria ser acrescida a visão sistêmica, transformando, como dizia em 1870 Olmsted (in: Laurie, 1983, p. 88), o ambiente e as paisagens não só em herança, como em patrimônio para a humanidade. Embora neste país de Terceiro Mundo, completamente endividado, venham-se tentando difundir a idéia de intromissão na soberania física, política..., ao mencionar-se troca de dívida por conservação de recursos naturais, podemos dizer que um primeiro passo foi dado na tentativa de quebrar a estrutura 'pensante' em vigor. Como diz Santos (1985), a compreensão da organização espacial, bem como de sua evolução, só se torna possível mediante a acurada interpretação do processo dialético entre formas, estruturas e funções através do tempo. Paisagem e ambiente são formados pelos fatos do passado e do presente. Suas formas podem ser as mesmas; sua estrutura também; mas sua função hoje é outra e não se restringe egoisticamente a uma escala local. O patrimônio ambiental não é mais, e por que não dizer, nunca foi de interesse e atuação circunscritos num limite puramente administrativo; basta perceber seus limites físicos e sua resposta na manutenção do equilíbrio natural. $\mathrm{Na}$ visão pequena e mesquinha, uma área de proteção ambiental ou o tombamento, por exemplo, de um bem comum, esbarra em limites de propriedade e de direitos, respondendo a um nível de equilíbrio individual de uma determinada variante. $O$ esgotamento de um recurso ou o desmatamento de uma área por exemplo, visto na escala e proporção corretas, vai alterar de forma irreversivel o equilibrio da biosfera. 
Assim esses questionamentos internos, adotados pelos movimentos ecológicos brasileiros (e estrangeiros), devem continuar acontecendo; as inovações por eles apresentadas podem não ser imediatamente aceitas, pois entram em contraposição à estrutura pensante, atuante e vigente no país. Mas, visto pelo prisma correto, a estrutura principal encontra-se numa escala muito maior que a do interesse local ou do "traço e ponto" administrativo. Em nome da manutenção do equilíbrio da biosfera e portanto de nossas vidas, é que as políticas econômicas, financeiras, etc., deveriam ser balizadas.

\section{BIBLIOGRAFIA}

AB'SABER, Azis N. Potencialidades Paisagísticas Brasileiras. IGEOG/USP, São Paulo, n. 55 (Geomorfologia)

BERRY, Brian. Mudanças Deliberadas nos Sistemas Espaciais. IGEOG/USP, São Paulo, n. 21 (Geografia e Planejamento)

CHACUR, Helena Napoleon Degreas. "Estado das Áreas de Proteção Ambiental e Tombamento - Comparação das APAs Corumbataí/Botucatu/Tejupá/Cajamar/Cabreúva e Jundiaí. In: Paisagem e Ambiente Ensaios II, Grupo de Disciplinas Paisagem e Ambiente, Depto. de Projeto, FAUUSP, São Paulo, 1987.

DREW, David. Processos Interativos Homem-Meio Ambiente. São Paulo, Difel, 1983.

KOSIK, Karrel. A Dialética do Concreto. Rio de Janeiro, Paz e Terra, 1979.

MAGNOLI, M.M.E. Martinelli. Espaços e Urbanização: uma Introdução a Aspectos da Paisagem Metropolitana . São Paulo, 1982. Tese (Livre-docência) - FAUUSP.

PELLEGRINO, Paulo R. M. Por um Design Ambiental espaço de amplicação a região Sorocaba. In: Paisagem e Ambiente: Ensaios I, Grupo de Disciplinas Paisagem e Ambiente do Departamento de Projeto, São Paulo, FAUUSP, 1986.

SANTOS, Milton. A Geografia e a Nova Dimensão do Planeta. Brasilia. Revista Brasileira de Tecnologia, v. 15, p. 13-21, set./out. 1984. . Espaço e Método. São Paulo, Nobel, 1986. 